\title{
PEMBUATAN KATROL SEBAGAI ALAT PERAGA BERBASIS MEKANIKAL DI SMA SEKOLAH RAKYAT BEKASI
}

Adhes Gamayel *

Sekolah Tinggi Teknologi Jakarta

\section{Ade Sunardi}

Sekolah Tinggi Teknologi Jakarta

\begin{abstract}
PULLEY PRODUCTION AS A MECHANICAL-BASED PROPS IN SMA SEKOLAH RAKYAT OF BEKASI. Pulley is a simple lift aircraft that enter the high school physics lesson. But the student of SMA Sekolah Rakyat (SR) Bekasi lack of understanding of the concept of the pulley so that did not like this subject. To overcome this issue, props with basic of mechanical where pulleys arrange on single and multilevel had been made. Activity methods are manufacture, trials the props, demontration and handover the props, processing data between pretest and posttest. Result show that student do the post test with good score after trial the props. Pulley props facilitate student of SMA SR Bekasi to better understand the concept of a simple lift aircraft.
\end{abstract}

KEYWORDS: Mechanical, Props, Pulleys, Simple Lift Air Craft.

* Corresponding Author: Sekolah Tinggi Teknologi Jakarta; Jl. Jatiwaringin Raya No. 42, Jatiwaringin, Pondokgede, Kota Bekasi, Jawa Barat 17411; Email: adhes@ @ttj.ac.id

\author{
Article History: Received: 19-9-2017; Revised: 16-10-2017; Accepted: 27-11-2017 \\ Permalink: http://ppm.ejournal.id/index.php/pengabdian/article/view/23 \\ How to cite (APA): Gamayel, A., \& Sunardi, A. (2017). Pembuatan katrol sebagai alat peraga berbasis mekanikal di SMA sekolah rakyat \\ Bekasi. Jurnal Pengabdian Pada Masyarakat, 2(2), 113-118.
}

This is an open access article distributed under the terms of the Creative Commons Attribution 4.0 International License, which permits unrestricted use, distribution, and reproduction in any medium, provided the original work is properly cited. @ 2017, Adhes Gamayel, Ade Sunardi.

\section{PENDAHULUAN}

Sesuai dengan UU Sisdiknas Nomor 20 Tahun 2003 yang mengamanatkan bahwa setiap warga Negara yang berusia 7-15 tahun wajib mengikuti pendidikan dasar. Dalam pasal 34 ayat 2 menyebutkan bahwa pemerintah dan pemerintah daerah menjamin terselenggaranya wajib belajar minimal pada jenjang pendidikan dasar tanpa memungut biaya, sedangkan dalam ayat 3 menyebutkan bahwa wajib belajar merupakan tanggung jawab negara yang diselenggarakan oleh lembaga pendidikan pemerintah, pemerintah daerah, dan masyarakat. Konsekuensi dari amanat undang-undang tersebut adalah pemerintah dan pemerintah daerah wajib memberikan layanan pendidikan bagi seluruh peserta didik pada tingkat pendidikan dasar (SD dan SMP) serta satuan pendidikan lain yang sederajat. Selain itu masyarakat umum bisa terlibat dalam pelaksanaan pendidikan gratis mulai dari tingkat SD, SMP dan SMA. 
Untuk mengurangi tingginya angka masyarakat yang tidak bersekolah SMA/Sederajat, maka dibentuk beberapa SMA dengan biaya gratis oleh elemen masyarakat seperti SMA Sekolah Rakyat (SR) Bekasi. Sekolah ini memiliki tujuan yaitu: 1) Mensukseskan program pendidikan dasar 12 tahun; 2) Memberikan kesempatan sekolah bagi masyarakat yang berprestasi tetapi kurang mampu dalam ekonomi keluarga; 3) Memberikan pemahaman kepada masyarakat akan pentingnya pendidikan bagi masa depan anak bangsa dan generasi mendatang

SMA SR Bekasi berlokasi di Kampung Belendung RT. 18 RW. 07 Desa Kedung Pengawas Kecamatan Cikarang Pusat Kabupaten Bekasi. Berdiri pada tanggal 1 Juni 2005 dengan jumlah siswa total sebanyak 400 siswa. SMA SR hanya memiliki alat peraga sederhana, seperti globe, peta, dan penggaris panjang. SMA SR Bekasi ini merupakan sekolah berbiaya gratis bagi para siswa siswi. Layanan pendidikan yang diberikan kepada siswa siswi adalah layanan pendidikan formal yang mengacu pada kurikulum Mendiknas. Disamping itu proses pembelajaran dan pembiayaan operasional sekolah seperti honor guru, biaya listrik, ATK, keamanan, kebersihan dan perawatan gedung ditanggung oleh para donatur tetap yang dihimpun oleh Yayasan Sekolah Rakyat Bekasi.

Fasilitas alat peraga yang kurang memadai, menyebabkan guru tidak maksimal dalam memberikan pemahaman kepada siswa khususnya pelajaran fisika. Agar terselenggara proses belajar mengajar yang menyenangkan, maka perlu ditingkatkan jumlah alat peraga yang dimiliki. Hal ini dapat menarik perhatian siswa dan dapat menumbuhkan minat untuk mengikuti pembelajaran IPA (Prasetyarini, 2013). Katrol merupakan pesawat angkat sederhana yang ada dalam materi IPA khususnya Fisika. Penggunaan katrol sebagai alat peraga berbasis mekanikal diharapkan dapat membantu proses belajar mengajar di SMA SR Bekasi baik dari segi siswa siswi maupun guru pengajar.

\section{METODE PELAKSANAAN}

Metode yang dilakukan adalah pembuatan desain alat peraga berbasis mekanikal seperti Gambar 1. Langkah berikutnya adalah proses pembuatan alat peraga seperti pemotongan logam, pengelasan logam, drilling (membuat lubang), dan grinding (penghalusan permukaan). Setelah proses pembuatan selesai, dilakukan proses uji coba alat peraga untuk memastikan alat peraga dapat dioperasikan dengan baik. Terakhir adalah penyerahan dan penyuluhan penggunaan alat peraga tersebut. 

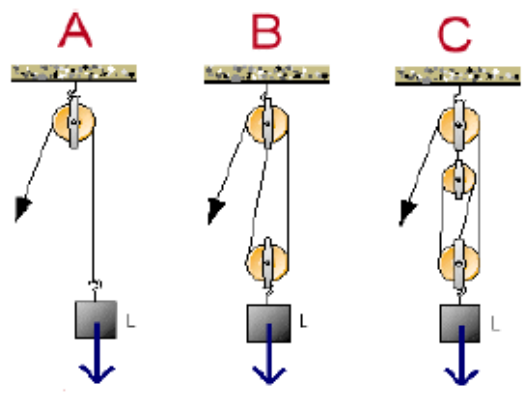

Gambar 1. Desain Katrol

\section{HASIL DAN PEMBAHASAN}

\section{Proses Pengerjaan alat peraga}

Setelah desain alat peraga selesai dibuat, maka dilakukan proses produksi pembuatan alat peraga tersebut. Tahapan pembuatan alat peraga yaitu, pemotongan logam, pengelasan, dan penghalusan bahan. Adapun proses pengerjaan terdiri dari

\section{Pembuatan kontruksi alat peraga}

Pembuatan kontruksi alat peraga dilakukan agar alat peraga memiliki kontruksi yang kokoh, sehingga saat dipakai tidak mudah rusak. Pembuatan kontruksi ini menggunakan proses pengelasan dengan menggunakan busur listrik.

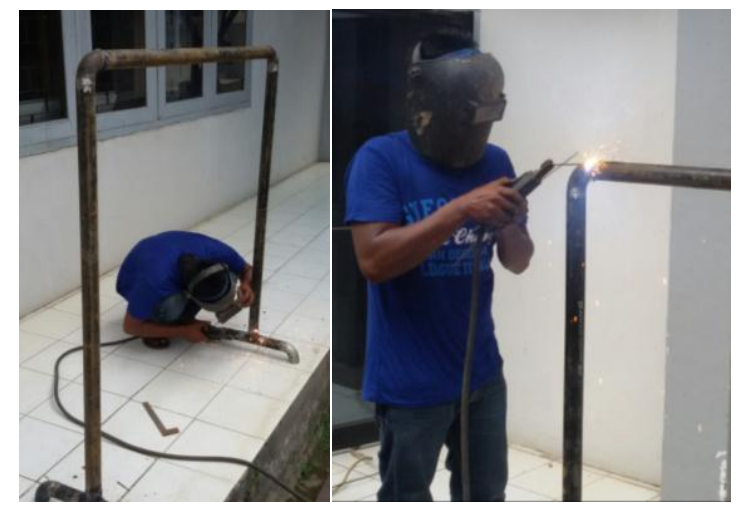

Gambar 2. Pembuatan Kontruksi Alat Peraga

(Sumber: Dokumentasi penulis)

\section{Pemasangan Katrol}

Pemasangan katrol dilakukan dengan metode pengelasan. Dalam satu kontruksi alat peraga, ada tiga titik penempatan katrol, sehingga panjang besi peletakan katrol dibagi menjadi tiga bagian secara proporsional. 


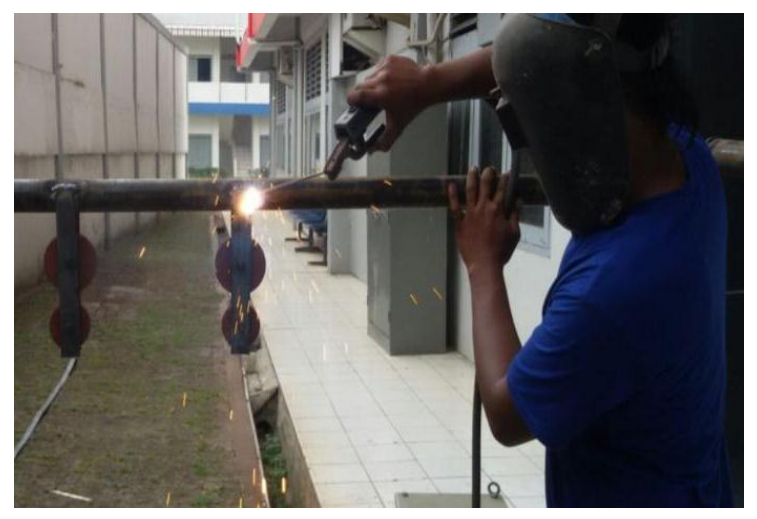

Gambar 3. Proses Pemasangan Katrol

(Sumber: Dokumentasi penulis)

\section{Uji Coba Alat Peraga}

Uji coba alat peraga dilakukan untuk memastikan sistem kerja berjalan dengan baik. Penentuan posisi katrol yang tidak liniear menyebabkan kerja katrol menjadi berat dan bergesekan dengan tali katrol. Disamping itu, uji coba ini untuk melihat apakah masing masing katrol dapat berputar dengan baik.

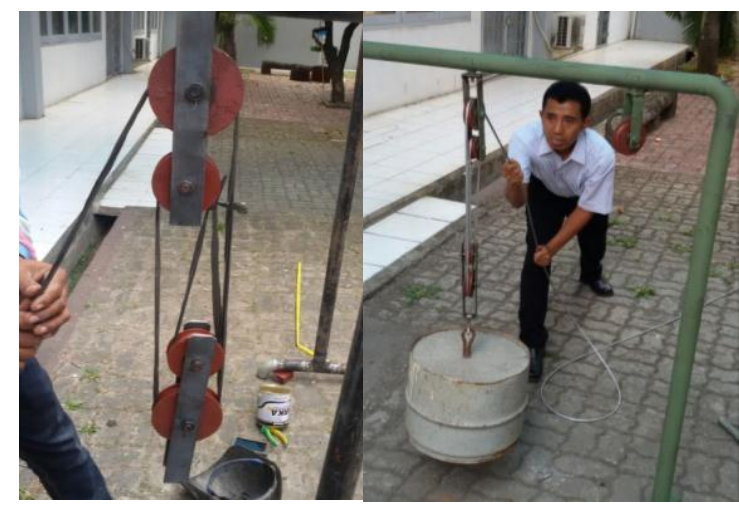

Gambar 4. Uji Coba Katrol Tanpa Beban dan Menggunakan Beban (sumber: dokumentasi penulis)

\section{Penyerahan Alat Peraga}

Telah dilakukan penyerahan alat peraga berbasis mekanikal berupa katrol dan diterima oleh kepala sekolah SMA SR Bekasi seperti pada Gambar 5 (a). Para siswa SMA SR melakukan percobaan menggunakan alat peraga katrol, dimana mereka merasakan perbedaan mengangkat beban dengan menggunakan beberapa sistem katrol yang berbeda seperti terlihat pada Gambar 5 (b). 


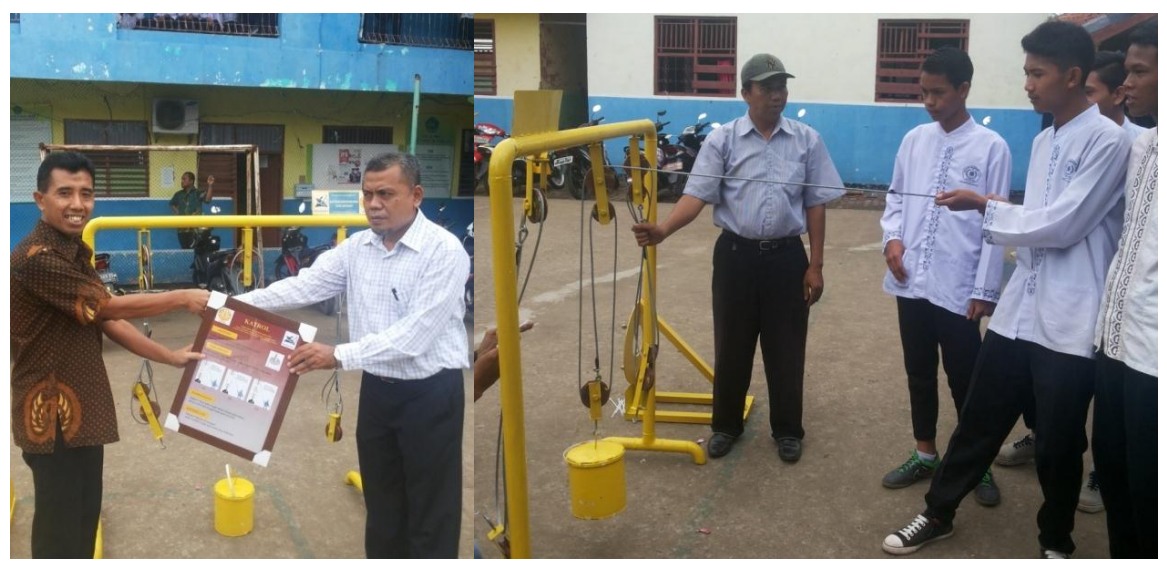

(a)

(b)

Gambar 5. (a) Penyerahan Alat Peraga Kepada Kepala Sekolah; (b) Percobaan Alat Peraga oleh Siswa SMA SR Bekasi

(Sumber: Dokumentasi penulis)

Sesaat sebelum siswa melakukan percobaan alat peraga katrol, mereka mengikuti pretest yang diadakan oleh tim IbM STTJ. Setelah selesai melakukan percobaan alat peraga, siswa mengikuti post-test. Dari hasil pretest dan post-test didapatkan perbedaan yang cukup besar dimana tingkat pemahaman siswa terhadap prinsip kerja katrol menjadi lebih paham sesaat setelah melakukan percobaan tersebut. Hasil pretest dan post-test ditampilkan pada Tabel 1.

Tabel 1. Hasil Pretest dan Post Test

\begin{tabular}{lcc}
\hline Keterangan & Pre test & Post Test \\
\hline Nilai Terendah & 35 & 75 \\
Nilai Tertinggi & 65 & 90 \\
Rata-rata & 43 & 85,4 \\
\hline
\end{tabular}

Pada Tabel 1, dapat dilihat bahwa alat peraga katrol yang dikembangkan memiliki dampak yang baik bagi pemahaman siswa terhadap pesawat angkat. Hal ini karena siswa mengamati dan merasakan perbedaan berat beban yang diangkat saat menggunakan jumlah katrol yang berbeda.

\section{SIMPULAN}

Berdasarkan hasil kegiatan membuat siswa SMA SR Bekasi lebih mudah memahami prinsip kerja Katrol setelah melakukan percobaan menggunakan katrol sebagai alat peraga berbasis mekanikal, dan menjadikan siswa SMA SR Bekasi 
menjadi lebih senang belajar fisika saat diberikan alat peraga untuk memahami konsep keilmuan.

Kegiatan pengabdian masyarakat ini, tim Ipteks bagi Masyarakat (IbM) Sekolah Tinggi Teknologi Jakarta (STTJ) berhasil menyelesaikan luaran berupa alat peraga dan poster.

\section{REFERENSI}

Azis, A., Yulianti, D., \& Handayani, L. (2006). Penerapan model pembelajaran kooperatif dengan memanfaatkan alat peraga sains fisika (materi tata surya) untuk meningkatkan hasil belajar dan kerjasama siswa. Jurnal Pendidikan Fisika Indonesia, 4(2), 94-99.

Gunawan. (1996). Peningkatan mutu proses belajar mengajar sekolah dasar. Bandung: Siger Tengah.

Juwairiyah, J. (2013). Alat peraga dan media pembelajaran kimia. Jurnal Visipena, 4(1), 1-13.

Prasetyarini, A. (2013). Pemanfaatan alat peraga ipa untuk peningkatan pemahaman konsep fisika pada siswa SMP Negeri I Buluspesantren Kebumen tahun pelajaran 2012/2013. RADIASI: Jurnal Berkala Pendidikan Fisika, 2(1), 7-10.

Purwanto, N. (1990). Psikologi pendidikan. Bandung: Remaja Rosdakarya.

Sudjana, N. (2000). CBSA: Dasar-dasar proses belajar mengajar. Bandung: Sinar Baru Algeandra.

Sudjana, N., \& Rivai, A. (1990). Media pembelajaran. Bandung: Sinar Baru Bandung.

\section{Ucapan Terimakasih}

Terimakasih disampaikan kepada Kementerian Riset, Teknologi, dan Pendidikan Tinggi melalui Ditjen Penguatan Riset dan Pengembangan yang telah memberikan dana hibah IbM untuk kegiatan pengabdian masyarakat ini. 